\title{
The social context and the need of information from patients with epilepsy: evaluating a tertiary referral service
}

\author{
0 contexto social e a necessidade de informações de pacientes com epilepsia: avaliando \\ um serviço terciário de referência
}

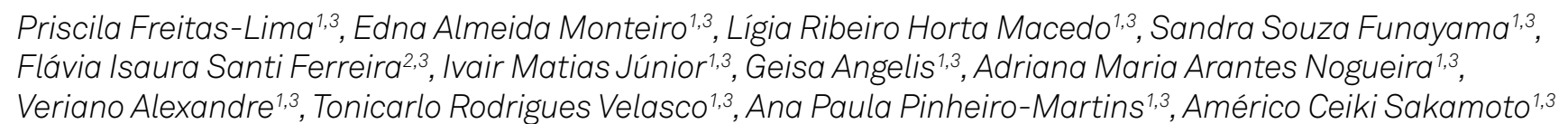

\begin{abstract}
Objective: Characterize the social profile and the need of information from patients with refractory epilepsy. Method: A semi-structured questionnaire was applied to 103 patients to investigate sociodemographic aspects, pharmacotherapy and any doubts about epilepsy. Results: Patients were highly dependent on having a free and accessible supply of antiepileptic drugs. Sixty-eight percent of the population was unemployed, and $26 \%$ confirmed receiving social security benefits due to epilepsy. Twenty-nine percent of the population reached high school. Eighty-five percent of the patients had at least one doubt about epilepsy; treatment and epilepsy aspects in general were the main topics. Conclusion: As observed in developed countries, patients with refractory epilepsy from a developing country also have high rates of unemployment and low educational levels. The results raise a concern about the need of information about epilepsy by patients and their families, urging the necessity to invest in strategies to solve this deficiency in knowledge.
\end{abstract}

Keywords: epilepsy, social evaluation, information, outpatient service.

\section{RESUMO}

Objetivo: Caracterizar o perfil social e a necessidade de informações por parte de pacientes com epilepsia refratária. Método: Um questionário semi-estruturado foi aplicado a 103 pacientes para investigar aspectos sociodemográficos, farmacoterapia e quaisquer dúvidas sobre epilepsia. Resultados: Os pacientes mostraram-se altamente dependentes de um fornecimento gratuito e acessível de drogas antiepilépticas. Sessenta e oito por cento da população estava desempregada, e 26\% confirmaram receber algum benefício social devido à epilepsia. Vinte e nove por cento da população alcançou ensino médio. Oitenta e cinco por cento dos pacientes tinha ao menos uma dúvida sobre epilepsia; tratamento e aspectos gerais da epilepsia foram os principais temas. Conclusão: Tal qual observado em países desenvolvidos, pacientes com epilepsia refratária em países em desenvolvimento também apresentam altas taxas de desemprego e baixos níveis educacionais. Os resultados são preocupantes no que diz respeito à necessidade de informações sobre epilepsia por parte dos pacientes e seus familiares, apontando a necessidade de se investir em estratégias que solucionem esta deficiência de conhecimento.

Palavras-chave: epilepsia, avaliação social, informação, serviço ambulatorial.

Epilepsy, a chronic disorder affecting $1 \%$ to $2 \%$ of the world population, is mainly characterized by the recurrence of epileptic seizures ${ }^{1}$. It has been observed, on few last decades, an increased concern from health care professionals towards other aspects related to the quality of life from patients with epilepsy that are not only the control of seizures recurrence $^{2,3,4,5}$. Publications suggest that patients might be treated in a broader approach, giving importance to psychosocial

'Universidade de São Paulo, Faculdade de Medicina de Ribeirão Preto, Ribeirao Preto SP, Brazil;

${ }^{2}$ Universidade de São Paulo, Faculdade de Ciências Farmacêuticas de Ribeirão Preto, Ribeirao Preto SP, Brazil;

${ }^{3}$ Hospital das Clínicas, Faculdade de Medicina de Ribeirão Preto, Ribeirao Preto, Brazil.

Correspondence: Priscila de Freitas-Lima; Universidade de São Paulo, Hospital das Clínicas, Faculdade de Medicina de Ribeirão Preto, Centro de Cirurgia de Epilepsia (CIREP / $4^{\circ}$ andar); Av dos Bandeirantes, 3900 - Monte Alegre; 14048-900 Ribeirão Preto SP, Brasil; E-mail: limapf12@gmail.com

Conflict of interest: There is no conflict of interest to declare.

Support: This work was supported by Conselho Nacional de Desenvolvimento Científico e Tecnológico, Brazil [schoolarship to P.F.L.]; Coordenação de Aperfeiçoamento de Pessoal de Nivel Superior, Brazil [schoolarship to F.I.S.F.] and Fundação de Amparo à Pesquisa do Estado de São Paulo, Brazil [schoolarship to I.M.J.]. The sponsors had no role in design or conduct of the study; collection, management, analysis or interpretation of the data; or preparation, review or approval of the manuscript.

Received 02 October 2014; Received in final form 13 November 2014; Accepted 02 December 2014. 
aspects, satisfaction with the medical treatment and their necessity to obtain information about epilepsy from health care professionals ${ }^{6,7}$.

Surveys conducted in different countries show that there are patients who do not know basic aspects related to the epilepsy and its treatment, and often have mistaken beliefs ${ }^{8,9}$. The patients' knowledge about their own medical condition is associated with a better physician-patient relationship, improved patients' ability to inform about their situation and better therapeutic compliance ${ }^{10}$.

The present study aimed to characterize the social profile and evaluate the need of information from adult patients with refractory epilepsy attending a tertiary referral service in Brazil.

\section{METHOD}

The protocol was approved by the Ribeirao Preto Clinical Hospital's Ethics Committee and was performed in accordance with ethical standards. The sample evaluated was composed of outpatients $\geq 18$ years old attending the refractory epilepsy clinic at the Ribeirao Preto Clinical Hospital, Brazil. In case of incapability to understand, the questionnaire was answered by the patient's responsible caregiver/accompanying family member. All subjects gave their informed consent prior to the inclusion in the study.

The semi-structured questionnaire was elaborated by the Brazilian Association for Epilepsy (Chapter: Ribeirao Preto) and applied to 103 patients (approximately 10\% of all adult patients attending the refractory epilepsy clinic), randomly chosen, while waiting to the medical visit. Questions evaluated sociodemographic factors and aspects related to pharmacotherapy, so as patients' preferences regarding the health service level and if they knew the Brazilian Association for Epilepsy. If patients had doubts about epilepsy, questions could be specified in an open field at the end of the questionnaire. Complementary clinical data was obtained from medical records. The SPSS $17.0^{\circ}$ software was used to verify for a possible relation between sociodemographic data and presence of doubts about epilepsy (Chi-square test, $\chi^{2}$ ). Level of significance adopted: $\mathrm{p}<0.05$.

\section{RESULTS}

\section{Patients and treatment}

Ninety-eight patients answered the questionnaire. The demographic characteristics of the sample population are displayed in Table 1.

All patients were in regular treatment. The mean number of antiepileptic drugs (AEDs) per patient was $2.6 \pm 0.7$ (mean \pm standard deviation, SD), ranging from one to four.
Table 1. Patients' clinical and demographic characteristics $(n=98)$,

\begin{tabular}{lc}
\hline Characteristics & Number of patients (\%) \\
\hline Sex & $54 \mathrm{~F}(55) ; 44 \mathrm{M}(45)$ \\
Age (years \pm SD) & $37.4 \pm 10.5$ \\
Age at epilepsy onset (years \pm SD) & $12.6 \pm 9.9$ \\
Epilepsy syndromes & \\
Localization-related epilepsies & $93(95)$ \\
$\quad$ Cryptogenic & 13 \\
Symptomatic & 80 \\
Generalized epilepsies & $2(2)$ \\
Idiopathic & 1 \\
Symptomatic & 1 \\
Undetermined whether focal or generalized & $3(3)$ \\
Seizure types ${ }^{1}$ & \\
Complex partial & $49(50)$ \\
Simple partial & $10(10)$ \\
Secondarily generalized tonic-clonic & $27(27)$ \\
Absence & $2(2)$ \\
Tonic & $7(7)$ \\
Clonic & $1(1)$ \\
Myoclonic & $1(1)$ \\
Primarily generalized tonic-clonic & $9(9)$ \\
Atonic & $2(2)$ \\
Not classified & $1(1)$ \\
Comorbidities ${ }^{2}$ & \\
Medical & $20(20)$ \\
Neurologic & $10(10)$ \\
Psychiatric & \\
(5/98); some patients presented more than one seizure type. ${ }^{2}$-fome patients \\
had more than one comorbidity. F: Female; M: Male; SD: Standard deviation.
\end{tabular}

Carbamazepine (CBZ) was the most commonly prescribed AED (Figure). Of the second generation AEDs, lamotrigine (LTG) was the most common. At the time of data collecting, LTG, TPM, vigabatrin (VGB) and gabapentin (GBP) were the second generation AEDs provided free of costs by the Brazilian public health care system, in addition to the first generation CBZ, phenytoin (PHT), phenobarbital (PB) and valproic acid (VPA). Within the 71 patients in treatment with $\geq 1$ second generation AED provided free of costs, 22 reported having difficulties to obtain their AEDs at the time of the interview (lack of medications at the health units). From the 82 patients in treatment with $\geq 1$ first generation AED provided free of costs, 54 patients (66\%) reported getting their AEDs in health units (free of costs), and 12 patients said they did not refer to the public health system to obtain their first generation AEDs. Sixteen patients did not answer to this question.

Regarding patients' preferences for sharing the medical care for epilepsy among different health services levels, approximately $27 \%$ of the patients confirmed receiving medical care with a neurologist both at the hospital and at another (primary or secondary) health care level. 


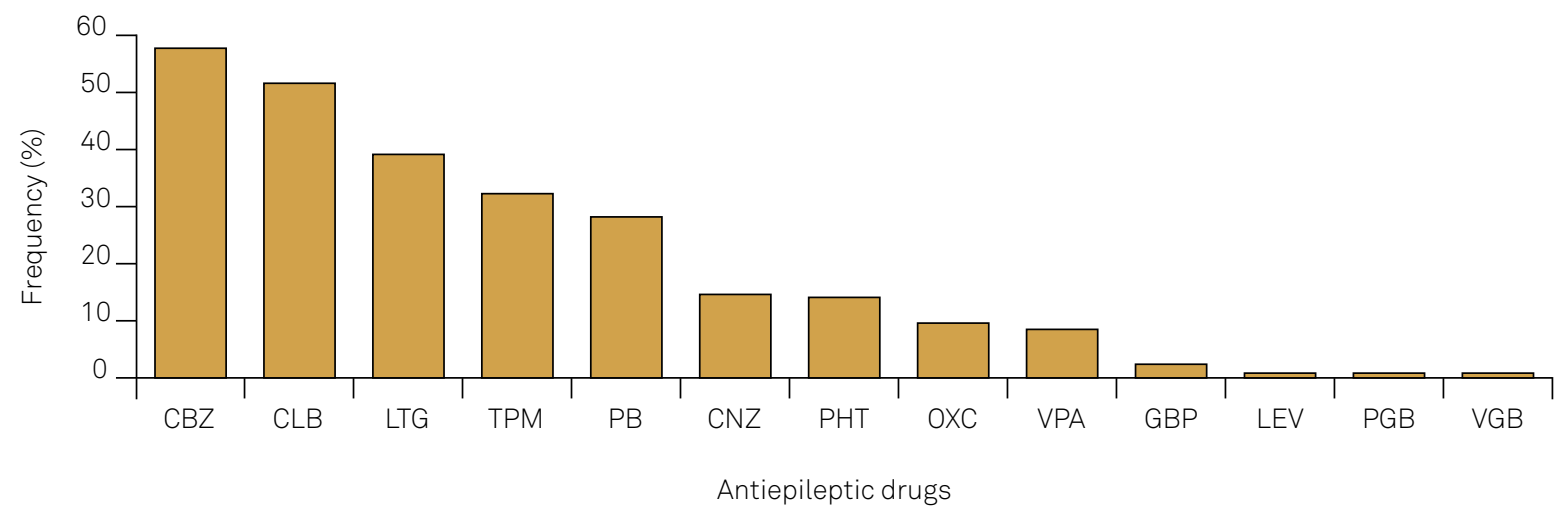

CBZ: Carbamazepine; CLB: Clobazam; LTG: Lamotrigine; TPM: Topiramate; PB: Phenobarbital; CNZ: Clonazepam; PHT: Phenytoin; OXC: Oxcarbazepine;VPA: Valproic Acid; GBP: Gabapentin; LEV: Levetiracetam; PGB: Pregabalim;VGB:Vigabatrine

Figure. Frequency of AEDs utilization $(n=98)$.

\section{Social aspects}

The majority of the patients (68\%) declared not to have a job at the time the study was conducted (Table 2). From these, only three individuals declared themselves as students. Regarding social security benefits such as pension or retirement, 26 patients $(26 \%)$ confirmed receiving social security benefits due to epilepsy.

\section{Doubts about epilepsy}

The questionnaire had an open field so patients and/or caregivers could express any doubts they might have about epilepsy (Table 3). Only 15 patients declared having no doubts. No significant relationship was found between the presence or absence of doubts and the level of education $\left(\chi^{2}=8.8 ; p=0.1\right)$, sex $\left(\chi^{2}=2.5 ; p=0.1\right)$ and mean age $\left(\mathrm{F}_{1 ; 2.22}=0.14\right)$.

According to Table 3, the most frequently asked topics referred to: (1) treatment, with doubts about a possible cure and/or surgery as the most frequent; (2) epilepsy in general ("what is epilepsy?" and "what causes epilepsy?", for example); (3) employment and social security benefits, including what limitations epilepsy inputs over job activities and what are the procedures to obtain social security benefits; and (4) nonspecific epilepsy questions (all patients with such questions reported as having "doubts about everything").

Patients were asked if they knew the Brazilian Association for Epilepsy; 23 patients (23\%) answered that they were aware of the organization.

\section{DISCUSSION}

Aspects related to social functioning are, in general, considered as highly relevant by patients with epilepsy and their family members ${ }^{11}$. Regardless of the sociodemographic context, patients worldwide, especially those with refractory
Table 2. Patients' social characteristics $(n=98)$.

\begin{tabular}{lc}
\hline Aspects & Number of patients (\%) \\
\hline Employment & \\
Employed & $31(32)$ \\
Unemployed & $67(68)$ \\
Social security benefits & \\
Retirement & $18(18)$ \\
Pension & $3(3)$ \\
Disability benefit & $8(8)$ \\
Other & $9(9)$ \\
Marital status & \\
Single (never married) & $44(45)$ \\
Married & $40(41)$ \\
Divorced & $7(7)$ \\
Widowed & $1(1)$ \\
Common-law marriage & $6(6)$ \\
Education (years) & \\
0 & $5(5)$ \\
1 to 4 & $22(22)$ \\
5 to 8 & $28(28)$ \\
9 to 11 & $29(29)$ \\
$>11$ & $3(3)$ \\
Special school & $11(11)$ \\
\hline Retirnentobtained due to &
\end{tabular}

Retirement obtained due to epilepsy.

epilepsy, present common characteristics that claim for the need of not only treating the seizures recurrence, but also of providing assistance for psychosocial aspects that are increasingly being recognized as significant for a well-succeeded treatment as a whole.

It is interesting to observe the relationship between a social (AEDs accessibility) and a clinical aspect (the characteristics of pharmacological treatment). As reviewed by Mbuba and co-workers ${ }^{12}$, the AEDs costs and accessibility are important factors behind the treatment gap seen in developing countries. The prescription patterns in our service are in congruence with the nationally-established determinants that 
Table 3. Doubts about epilepsy $(n=98)$.

\begin{tabular}{lc}
\hline Topics and main questions & Number of patients (\%) ${ }^{1}$ \\
\hline Treatment & $42(43)$ \\
Cure & \\
Surgery & \\
Medications & $30(31)$ \\
Epilepsy & \\
What is epilepsy & \\
Cause & \\
Symptoms & $13(13)$ \\
Seizures & \\
Employment and social security benefits & \\
Limitations over job activities & $11(11)$ \\
Obtaining a social security benefit & \\
Nonspecific &
\end{tabular}

Some patients had more than one type of question.

regulate the use of second generation AEDs (considered as high cost medications) for treatment of refractory epilepsy in the Brazilian public health care system. The restricted access to new AEDs in public services certainly plays a role on the treatment profile demonstrated in Figure, especially regarding the low frequencies of use of modern agents such as oxcarbazepine (OXC), levetiracetam (LEV) and pregabalin (PGB), widely used in developed countries ${ }^{13,14}$. Although we have not directly evaluated the patients' satisfaction with the health care service provided, it is known that the burden of the medication costs and the accessibility difficulties are determinants for the treatment success and, consequently, for patients' satisfaction ${ }^{12,15}$.

Approximately $27 \%$ of the evaluated patients confirmed sharing the medical care between the hospital and another health care level. Patients with refractory epilepsy usually need to be followed in specialized tertiary services due to the complexity of the neurological condition and the frequently seen comorbidities (Table 1). In general, patients in such circumstances are satisfied with the tertiary service, although they still have criticisms regarding the resolvability of their seizures, the short period of time spent in medical visits, and the deficiency in information provision both in general aspects and specifically to their $\operatorname{cases}^{7,16,17,18}$. As discussed by Poole and colleagues ${ }^{7}$, such critiques of the tertiary level service commonly motivate the patients to, in parallel, look for medical care on other levels, where they report having more personalized and familial care. Nonetheless, sharing health care in different levels do not necessarily result objectively in higher quality of care, as highlighted by Pugh and co-workers ${ }^{19}$.

The majority of the patients confirmed not to have a job by the time of the interview (Table 2). In fact, labor restrictions are frequent in patients with epilepsy, especially in those with refractory epilepsy ${ }^{2}$. The implications of unemployment or non-formal job on patients quality of life are being increasingly investigated ${ }^{2,45}$. Although part of the patients are indeed unable to work, the prejudice by employers is still a significant barrier faced by the patients able to work, as highlighted by Smeets and colleagues ${ }^{20}$ in a vast literature review.

Corroborating previous findings, the patients included in our study presented low educational levels; less than onethird of the sample reached high school and only $3 \%$ studied at university level (Table 2). Additionally relevant are the five patients who stated never having gone to any school. In Brazil, no schooling is equivalent to illiteracy, since homeschooling, common in other countries, is not recognized as formal education. Certainly, the inclusion bias present in our study (only patients with refractory epilepsy) plays a role in the educational level found. High frequency of seizures, polytherapies, adverse events provoked by AEDs and comorbidities (especially psychiatric), among other factors closely related to refractory epilepsy, contributed to high levels of school dropout ${ }^{21}$. Nonetheless, surveys performed in different sociodemographic contexts indicate higher numbers of patients with refractory epilepsy who attained university education, suggesting that simply having epilepsy, even if refractory, do not limit access to education. The socio-cultural environment, independent from the disease, also has a relevant influence on patients' educational progresses ${ }^{22}$.

Our results corroborate with data that emphasizes the need of obtaining information about epilepsy by patients and their family members ${ }^{6,7,8,9,17,18,23,24,25}$. It is important to distinguish what is to evaluate the level of knowledge of the patients from what is to evaluate their need of information. Jarvie and co-workers published widely used questionnaires that measure (based on "true/false" questions) the patients' level of knowledge about epilepsy ${ }^{26,27}$. Although such questionnaires indicate the deficient areas of knowledge based on the high rates of wrong answers, we believe that an open answer to the question "Do you have any doubt about epilepsy? If yes, what is (are) your doubt(s)?" indicates more precisely the needs of the patients since it focuses on what is really relevant for them. In addition, as highlighted by Goldstein and colleagues ${ }^{17}$, the demand for information is not necessarily related to the level of knowledge already acquired by the patients.

The doubts were more frequently related to the treatment and cure of epilepsy, possible causes and the disease characteristics (Table 3). Through the perspective of health care professionals habituated to work with patients with epilepsy, these can be considered basic questions. However, questions such as "what is epilepsy?", "what causes epilepsy?", "does epilepsy have a cure?" are recurrent even in more favorable socioeconomic contexts ${ }^{6,7,9,17,18,25}$, in groups with controlled epilepsy ${ }^{6,718}$ and in different levels of health service (primary and/or secondary levels) , $7,8,18,25$. These doubts can be more common than supposed, but are not exteriorized because some patients feel that the physicians are inaccessible and do not care about their questions ${ }^{6,24}$. Also, the short period of time spent at the medical visits, specially at the tertiary level, 
impairs the establishment of a dialogue that informs the patients considering their specific needs of information, even if basic $^{8,24}$. However, patients with refractory epilepsy frequently have cognitive and memory impairments, hence, it is possible that such patients were informed, but they did not understand and/or retained the information ${ }^{7,17,24}$.

Independently from the reasons behind such questions, the data found reinforce the need of investments on educational strategies. There is no consensus about the best way to deal with the information provision. Some authors suggest the incorporation of multidisciplinary teams (psychologists, social workers, nurses) to the health services ${ }^{16,17,18}$. Some authors stress the effectiveness of distributing instructional materials to patients and families ${ }^{7,17,18}$, and others highlight the role of recommending associations with whom patients can establish a convenient contact when searching for information ${ }^{18,25,28}$. The low percentage of patients who confirmed having knowledge of the Brazilian Association for Epilepsy opens the perspective of the need to improve strategies to ameliorate the need of information about epilepsy expressed by our patients and their families. There are publications that support the implementation of psycho-educational groups as a way to inform patients about epilepsy ${ }^{8,29}$. As discussed by Prinjha and colleagues, adopting only one strategy to instruct the patients may not be enough to overcome all demands ${ }^{25}$.

In spite of the value that the present study portrays, limitations must be taken into account so the data can be interpreted with consideration to some singularities. The inclusion of patients with refractory epilepsy does not necessarily represent all the patients with epilepsy. These are patients in a more severe medical condition which generally have comorbidities that influence psychosocial factors, and patients with comorbidities were not excluded. Although we acknowledge the importance of applying a semi-structured questionnaire, not adopting validated tools resulted in difficulties comparing our data to those in other studies. In addition, deeper investigations are needed to understand if the patients have more general doubts about epilepsy or if their doubts are only related to their own conditions, and if the profile of doubts from the families is different from that presented by the patients.

In conclusion, although inserted in a sociodemographic context different from that usually found in the literature, the patients with refractory epilepsy from a developing country such as Brazil similarly have high rates of unemployment, low educational levels and a tendency to be not married. The data presented raises a concern about the demand for information about epilepsy by the patients and their families. As this need is present in different social, cultural and economic scenarios, it is evident that there is a high need to invest in strategies to solve this deficiency in knowledge.

\section{ACKNOWLEDGMENTS}

The authors would like to thank Dr Ariel Topletz for assistance with the English editing.

\section{References}

1. Ngugi AK, Bottomley C, Kleinschmidt I, Sander JW, Newton CR. Estimation of the burden of active and life-time epilepsy: a meta-analytic approach. Epilepsia. 2010;51(5):883-90. http://dx.doi.org/10.1111/j.1528-1167.2009.02481.x

2. Viteva E. Impact of social factors on the quality of life of patients with refractory epilepsy. Acta Neurol Taiwan. 2013;22(2):51-8.

3. Cramer JA. Quality of life for people with epilepsy. Neurol Clin. 1994;12(1):1-13

4. Lu B, Elliott JO. Beyond seizures and medications: normal activity limitations, social support, and mental health in epilepsy. Epilepsia. 2011;53(2):e25-8. http://dx.doi.org/10.1111/j.1528-1167.2011.03331.x

5. Sherman EM. Maximizing quality of life in people living with epilepsy. Can J Neurol Sci. 2009;36 Suppl 1:S17-24.

6. Buck D, Jacoby A, Baker GA, Graham-Jones S, Chadwick DW. Patients' experiences of and satisfaction with care for their epilepsy. Epilepsia 1996;37(9):841-9. http://dx.doi.org/10.1111/j.1528-1157.1996.tb00036.x

7. Poole K, Moran N, Bell G, Solomon J, Kendall S, McCarthy M et al. Patients' perspectives on services for epilepsy: a survey of patient satisfaction, preferences and information provision in 2394 people with epilepsy. Seizure. 2000;9(8):551-8. http://dx.doi.org/10.1053/seiz.2000.0450
8. Elliott J, Shneker B. Patient, caregiver, and health care practitioner knowledge of, beliefs about, and attitudes toward epilepsy. Epilepsy Behav. 2008;12(4):547-56. http://dx.doi.org/10.1016/j.yebeh.2007.11.008

9. Long L, Reeves AL, Moore JL, Roach J, Pickering CT. An assessment of epilepsy patients' knowledge of their disorder. Epilepsia. 2000;41(6):727-31. http://dx.doi.org/10.1111/j.1528-1157.2000.tb00235.x

10. Lorig K. Self-management education: more than a nice extra. Med Care. 2003;41(6):699-701. http://dx.doi.org/10.1097/01.MLR.0000072811.54551.38

11. Suurmeijer TP, Reuvekamp MF, Aldenkamp BP. Social functioning, psychological functioning, and quality of life in epilepsy. Epilepsia. 2001;42(9):1160-8. http://dx.doi.org/10.1046/j.1528-1157.2001.37000.x

12. Mbuba CK, Ngugi AK, Newton CR, Carter JA. The epilepsy treatment gap in developing countries: a systematic review of the magnitude, causes, and intervention strategies. Epilepsia. 2008;49(9):1491-503. http://dx.doi.org/10.1111/j.1528-1167.2008.01693.x

13. Landmark CJ, Rytter E, Johannessen SI. Clinical use of antiepileptic drugs at a referral centre for epilepsy. Seizure. 2007;16(4):356-64. http://dx.doi.org/10.1016/j.seizure.2007.02.006 
14. Malerba A, Ciampa C, De Fazio S, Fattore C, Frassine B, La Neve A et al. Patterns of prescription of antiepileptic drugs in patients with refractory epilepsy at tertiary referral centres in Italy. Epilepsy Res. 2010;91(2-3):273-82. http://dx.doi.org/10.1016/j.eplepsyres.2010.08.002

15. Jennum P, Gyllenborg J, Kjellberg J. The social and economic consequences of epilepsy: a controlled national study. Epilepsia. 2011;52(5):949-56. http://dx.doi.org/10.1111/j.1528-1167.2010.02946.x

16. Upton D, Thompson PJ, Duncan JS. Patient satisfaction with specialized epilepsy assessment and treatment. Seizure. 1996;5(3):195-8. http://dx.doi.org/10.1016/S1059-1311(96)80035-5

17. Goldstein LH, Minchin L, Stubbs P, Fenwick PB. Are what people know about their epilepsy and what they want from an epilepsy service related? Seizure. 1997;6(6):435-42. http://dx.doi.org/10.1016/S1059-1311(97)80017-9

18. Jain P, Patterson VH, Morrow JI. What people with epilepsy want from a hospital clinic. Seizure. 1993;2(1):75-8. http://dx.doi.org/10.1016/S1059-1311(05)80106-2

19. Pugh MJ, Berlowitz DR, Rao JK, Shapiro G, Avetisyan R, Hanchate A et al. The quality of care for adults with epilepsy: an initial glimpse using the QUIET measure. BMC Health Serv Res. 2011;11(1):1. http://dx.doi.org/10.1186/1472-6963-11-1

20. Smeets VM, van Lierop BA, Vanhoutvin JP, Aldenkamp AP, Nijhuis FJ. Epilepsy and employment: literature review. Epilepsy Behav. 2007;10(3):354-62. http://dx.doi.org/10.1016/j.yebeh.2007.02.006

21. Aguiar BV, Guerreiro MM, McBrian D, Montenegro MA. Seizure impact on the school attendance in children with epilepsy. Seizure. 2007;16(8):698-702. http://dx.doi.org/10.1016/j.seizure.2007.05.013
22. Social aspects of epilepsy in the adult in seven European countries. The RESt-1 Group. Epilepsia. 2000;41(8):998-1004. http://dx.doi.org/10.1111/j.1528-1157.2000.tb00285.x

23. Hayden M, Penna C, Buchanan N. Epilepsy: patient perceptions of their condition. Seizure. 1992;1(3):191-7. http://dx.doi.org/10.1016/1059-1311(92)90025-V

24. Chappell B. Epilepsy: patient views on their condition and treatment. Seizure. 1992;1(2):103-9. http://dx.doi.org/10.1016/1059-1311(92)90007-N

25. Prinjha S, Chapple A, Herxheimer A, McPherson A. Many people with epilepsy want to know more: a qualitative study. Fam Pract. 2005;22(4):435-41. http://dx.doi.org/10.1093/fampra/cmi024

26. Jarvie S, Espie CA, Brodie MJ. The development of a questionnaire to assess knowledge of epilepsy: 1--General knowledge of epilepsy. Seizure. 1993;2 179185. http://dx.doi.org/10.1016/S1059-1311(05)80125-6

27. Jarvie S, Espie CA, Brodie MJ. The development of a questionnaire to assess knowledge of epilepsy: 2--Knowledge of own condition. Seizure. 1993;2(3):187-93. http://dx.doi.org/10.1016/S1059-1311(05)80126-8

28. Pugh MJ, Berlowitz DR, Montouris G, Bokhour B, Cramer $J A$, Bohm V et al. What constitutes high quality of care for adults with epilepsy? Neurology. 2007;69(21):2020-7. http://dx.doi.org/10.1212/01.WNL.0000291947.29643.9

29. May TW, Pfafflin M. The efficacy of an educational treatment program for patients with epilepsy (MOSES): results of a controlled, randomized study. Modular Service Package Epilepsy. Epilepsia. 2002;43(5):539549. http://dx.doi.org/10.1046/j.1528-1157.2002.23801.x 